\title{
Is there an association between platelet and blood inflammatory indices and the risk of gestational diabetes mellitus?
}

\author{
Mahta Abbasi Fashami, MCs student', Sepideh Hajian, PhD², Maryam Afrakhteh, MD², \\ Mehdi Khabaz Khoob, PhD ${ }^{4}$ \\ ${ }^{1}$ Student Research Committee, ${ }^{2}$ Midwifery and Reproductive Health Research Center, School of Nursing and Midwifery, ${ }^{3}$ Department of Obstetrics and
Gynecology, School of Medicine, Shahid Beheshti University of Medical Sciences; ${ }^{4}$ Department of Epidemiology, Noor Research Center for Ophthalmic
Epidemiology, Noor Eye Hospital, Tehran, Iran
}

\section{Objective}

Gestational diabetes mellitus (GDM) is the most prevalent medical complication in pregnancy. Early diagnosis of GDM can influence maternal/neonatal outcomes. To assess the association between platelet and blood inflammatory indices and the risk of GDM occurrence using the complete blood count (CBC) test. We also aimed to determine the sensitivity of each parameter for an early screening of this disorder during pregnancy.

\section{Methods}

This case-control study included 2 groups of 110 pregnant women with and without GDM. The women in each group were compared after the routine screening for GDM and after the CBC test at 24-28 weeks' gestation after being matched according to the inclusion criteria. Data were analyzed using SPSS version 16 and Medcalc version 14.8.1 software.

\section{Results}

There were statistically significant intergroup differences in white blood cell (WBC) count, platelet count, mean platelet volume (MPV), plateletcrit (PCT), MPV to platelet ratio, platelet to lymphocyte ratio, and Rh values. The values of lymphocyte count, neutrophil count, neutrophil to lymphocyte ratio, and blood group were not significantly different between groups. The logistic regression analysis showed the predictive values of WBC, platelet, MPV, and PCT in GDM. According to the receiver operating characteristic curve for all 3 variables, the level below the PCT chart was more than that of the others.

\section{Conclusion}

Increasing platelet and inflammatory indices on the CBC test in the second trimester of pregnancy seemed to be associated with the probability of GDM occurrence.

Keywords: Gestational diabetes mellitus; Blood cell counts; Blood platelets

\section{Introduction}

Gestational diabetes mellitus (GDM) is among the most common chronic diseases during pregnancy; in fact, it was recognized by one study as the most common medical condition in pregnancy [1]. GDM predominantly occurs during pregnancy in women whose pancreatic function is insufficient to overcome the insulin resistance caused by pregnancy [2]. Despite more than 50 years of research, no general agree-

Received: 2019.08.16. Revised: 2019.10.17. Accepted: 2019.10.28.

Corresponding author: Sepideh Hajian, $\mathrm{PhD}$

Midwifery and Reproductive Health Research Center, Shahid Beheshti University of Medical Sciences, Vali Asr Ave., Ayatollah Rafsanjani Cross Road, Niayesh Complex, Tehran 1985717443, Iran

E-mail: S.hajian@sbmu.ac.ir

https://orcid.org/0000-0002-3368-0036

Articles published in Obstet Gynecol Sci are open-access, distributed under the terms of the Creative Commons Attribution Non-Commercial License (http://creativecommons. org/licenses/by-nc/3.0/) which permits unrestricted non-commercial use, distribution, and reproduction in any medium, provided the original work is properly cited.

Copyright $\odot 2020$ Korean Society of Obstetrics and Gynecology 


\title{
Obstetrics \& Gynecology Science
}

\author{
Vol. 63, No. 2, 2020
}

ment on the screening method of GDM has been achieved [1]. The worldwide estimated prevalence of GDM is $13.2 \%$ [3]. The prevalence of GDM in the most recent Iranian study was reported as $81.8 \%$ [4]. Also, the rate of GDM relapse is reportedly 30-69\% [5]. Early screening for the detection of GDM can prevent maternal/fetal/neonatal outcomes such as preeclampsia, cesarean section, polyhydramnios, fetal macrosomia, instrumental labor, and prenatal mortality [6-8]. According to International Diabetes Federation guidelines, the diagnosis of GDM occurs when a glucose tolerance test performed at 24-28 weeks of pregnancy reveals a fasting blood glucose greater than 92, glucose level 1 hour after ingesting $75 \mathrm{~g}$ of glucose of up to $180 \mathrm{mg} / \mathrm{dL}$, or a glucose level 2 hours after ingesting $75 \mathrm{~g}$ of glucose greater than $153 \mathrm{mg} / \mathrm{dL}$ [9]. The pathophysiological process of diabetes occurs weeks to months before the diagnosis, and factors associated with the disease can be present in the blood before the clinical diagnosis of GDM is made [10]. A high level of placental lactogen hormone is associated with increased lipolysis, and the release of free fatty acids may increase insulin resistance [1]. On the other hand, chronic and mild inflammation are considered key components of the pathogenesis of insulin resistance and type 2 diabetes [11].

Among immunity elements, neutrophils, lymphocytes, and platelets play an important role in controlling inflammation. An increased count of leukocytes, especially neutrophils, is seen in both chronic and acute inflammation $[12,13]$. The platelet to lymphocyte ratio (PLR) and neutrophil to lymphocyte ratio (NLR) as inflammatory indices can be easily and inexpensively measured using this test [14]. Platelet indices including platelet count, mean platelet volume (MPV), platelet distribution width (PDW), plateletcrit (PCT), and mean platelet volume to platelet (MPR) ratio are derived from the results of a complete blood count (CBC) [15]. CBC and its differential count are inexpensive and convenient tests that can provide important information for diagnosing disease [16]. Various studies have suggested changes in some indicators including blood cells and platelets in GDM. In a metaanalysis study of 191 observational studies consisting of 1,361 women with GDM and 1,911 non-diabetic women, MPV values increased in the GDM group [17]. On the other hand, a cross-sectional study in Guangzhou, China [18], showed that in 302 pregnant women with GDM and 310 non-diabetic women, significant increases in white blood cells (WBCs), red blood cells, and plaques were significantly higher in pregnant women with GDM than in those without GDM. However, in a cross-sectional study of 20,128 people in Nangbo, China, no statistically significant difference between platelet and PDW levels, in diabetic and non-diabetic groups was reported ( $P>0.05)$ [19].

Given the contradictory results of these indices and a lack of Iranian studies, this study aimed to investigate the association between platelet and blood inflammatory indices and the risk of GDM occurrence using maternal $C B C$ sampling in the second trimester of pregnancy.

\section{Materials and methods}

This case-control study was conducted from January to October 2018 and included 2 groups consisting of 220 healthy pregnant women $(n=110)$ and women with GDM $(n=110)$ referred to the midwifery clinic of Shohada-e-Tajrish Hospital, Tehran, Iran. The minimum sample size for each group was calculated using the following formula $[20,21]$ :

$$
\mathrm{n}=\frac{\left(\mathrm{z}_{1-\frac{\alpha}{2}}+\mathrm{z}_{1-\beta}\right)^{2} *\left(\mathrm{Sd}_{1}^{2}+\mathrm{Sd}_{2}^{2}\right)}{\left(\mu_{1}-\mu_{2}\right)^{2}}
$$

At a: $0 / 05$ and $80 \%$ power.

Written informed consent was provided by all participants. Demographic data including age, gestational weeks, education level, and occupations of the mother and father were collected via interview. Pre-pregnancy weights and blood types were collected from their medical files. Each subject's height was measured by the researcher and the body mass index (BMI) was calculated. Also, due to the effect of increasing the number of pregnancies on the risk of GDM, sampling was performed only from primiparous mothers and mothers with a second pregnancy who had healthy children. Sampling in both groups was performed using the convenience method from pregnant women referred to the midwifery clinic of Shohada-e-Tajrish Educational Hospital in Tehran, Iran.

The 2-hour oral glucose tolerance test with $75 \mathrm{~g}$ of oral glucose and CBC tests were performed at weeks 24-28; if GDM was confirmed by a gynecologist based on the national GDM screening guideline, the women were continuously recruited using those criteria.

The inclusion criteria were as follows: gestational age 


\section{Obstetrics \& Gynecology Science}

Mahta Abbasi Fashami, et al. Platelets and gestational diabetes mellitus

24-28 weeks based on last menstrual period or ultrasound in the first trimester of pregnancy, BMI of 18.5-29.9 before pregnancy, no history of GDM no overt diabetes, no family history of type 2 diabetes, singleton spontaneous pregnancy, no hookah use or cigarette smoking, no drug or alcohol use, no medication use other than supplements, no previous/ current infectious disease, and no medical or obstetric disorders in the current pregnancy (e.g., cardiovascular disease, thyroid diseases, polycystic ovary syndrome). Unwillingness to cooperate with this study or a diagnosis other than GDM were the exclusion criteria. Next, using the group matching method, sampling for the control group was performed from women at low risk of developing GDM. For the group matching, an eligible pregnant woman was first entered into the case group; then, using the individual matching method, a subject of the same age, parity, and BMI was selected for the control group. The procedure was repeated for all cases included in the study until the desired study sample was achieved.

Blood samples were taken from pregnant women at Shohada-e-Tajrish Hospital at 24-28 weeks' gestation. Platelet and inflammatory parameters in the CBC were compared between groups. The correlations between those values and the incidence of GDM was compared and analyzed.

\section{Screening for gestational diabetes mellitus}

GDM screening was performed at 24-28 weeks of gestation for all pregnant women. A fasting blood sample was taken from all pregnant women for glucose monitoring. It was repeated 1 and 2 hours after the ingestion of $75 \mathrm{~g}$ of glucose. The normal fasting blood glucose should be less than $92 \mathrm{mg} / \mathrm{dL}$, the level at 1 hour later should be less than $180 \mathrm{mg} / \mathrm{dL}$, and that at 2 hours later should be less than $153 \mathrm{mg} / \mathrm{dL}$. If any of the levels exceeded these limits, GDM was diagnosed.

\section{Laboratory analyses}

Blood samples were taken for the analysis of CBC and GTT values in the morning after an 8-hour fast. For this purpose, $5 \mathrm{~mL}$ of intravenous blood was collected from the antecubital vein with minimal trauma into a tube containing ethylenediaminetetraacetic acid. Blood samples were analyzed within 1 hour after collection. For this purpose, blood serum samples were separated in tubes using a centrifuge at 3,000 $\times$ g for 10 minutes. The specimens were then placed in a Sysmax K-1000 Hemato Analyzer tube (Sysmex Corporation, Kobe,
Japan) for the CBC. Serum glucose levels were assessed using spectrophotometry. A Hitachi 912 Auto-Analyzer (Hitachi, Tokyo, Japan) and Bionik Glucose Kit (Bionik, Tehran, Iran) were used to measure blood glucose.

Instrument reliability was verified using the calibration method and blood glucose kit daily, 3 times in the morning, evening, and night shifts, using special calibration solutions.

\section{Statistical analysis}

SPSS software version 16 (IBM Inc., Chicago, IL, USA) was used to analyze the data using the 2 -independent samples t-test, Mann-Whitney $U$ test, and logistic regression tests. MedCalc software version 14.8.1 (MedCalc Software, Mariakerke, Belgium) was used to assess the cutoff points in GDM-dependent variables and determine their sensitivities and specificities.

\section{Results}

Given the matching of the most important demographic and medical variables in the groups, no statistically significant intergroup differences were noted (Table 1). The majority of women $(43.6 \%)$ in both groups had a secondary education level. Most were housewives (79\%) with self-employed husbands (35.4\%). The laboratory findings showed no significant intergroup differences in lymphocyte counts, neutrophil counts, NLR, and blood group variables (Table 2).

WBC, platelet, MPV, PCT, MPR, PLR, and Rh variables were significantly higher in the GDM group than in the control group. Also, more women with GDM were Rh-positive. To

Table 1. Means, standard deviations, and correlations of demographic and medical data

\begin{tabular}{lcccc}
\hline Variables & $\begin{array}{c}\text { Total } \\
(\mathbf{n = 2 2 0})\end{array}$ & $\begin{array}{c}\text { GDM } \\
(\mathbf{n}=\mathbf{1 1 0})\end{array}$ & $\begin{array}{c}\text { Healthy } \\
(\mathbf{n}=\mathbf{1 1 0})\end{array}$ & $\boldsymbol{P}$-value \\
\hline Age (year) & $28.6 \pm 6.1$ & $29.3 \pm 5.9$ & $27.9 \pm 6.2$ & 0.91 \\
Parity & $1.50 \pm 0.40$ & $1.56 \pm 0.40$ & $1.60 \pm 0.40$ & 0.46 \\
$\begin{array}{c}\text { Gestational } \\
\text { age (week) }\end{array}$ & $24.80 \pm 0.86$ & $24.80 \pm 0.89$ & $24.70 \pm 0.83$ & 0.30 \\
Weight $(\mathrm{kg})$ & $66.1 \pm 9.1$ & $65.0 \pm 8.9$ & $67.2 \pm 9.1$ & 0.76 \\
Height $(\mathrm{cm})$ & $161.0 \pm 5.9$ & $160.2 \pm 6.0$ & $161.7 \pm 5.7$ & 0.12 \\
BMl $\left(\mathrm{kg} / \mathrm{m}^{2}\right)$ & $25.5 \pm 2.8$ & $25.4 \pm 2.8$ & $25.6 \pm 2.7$ & 0.29 \\
\hline
\end{tabular}

Values are presented as mean \pm standard deviation.

GDM, gestational diabetes mellitus; BMI, body mass index. 


\section{Obstetrics \& Gynecology Science}

Vol. 63, No. 2, 2020

control for the simultaneous effects of other variables on GDM using logistic regression, increasing values of PCT, WBC, platelet, and MPV were significantly correlated with GDM (Table 3). The receiver operating characteristic (ROC) chart showed that in increase of 0.2 points in PCT was the most closely related, with a sensitivity, specificity, positive predictive value, and negative predictive value of $67.3,70$, 69.1, and 68.1, respectively (Table 4). PCT had the highest area under the curve (0.766) for predicting GDM (Fig. 1).

\section{Discussion}

Our study results suggested that PCT value in the second trimester had the highest correlation with the occurrence of GDM. However, based on the contractual classification system, the surface below the ROC curve in the range of 70-80 was not a strong predictor of clinical sensitivity or specificity [22]. Since there is no a practical way to predict maternal GDM before screening tests, the early detection of inflammatory and platelet-enhancing indicators using the $C B C$ test in the first half of pregnancy can help the assessment of mater-

Table 2. Means, standard deviations, and correlations of laboratory data

\begin{tabular}{lcccc}
\hline Variables & $\begin{array}{c}\text { Total } \\
(\mathbf{n}=\mathbf{2 2 0})\end{array}$ & $\begin{array}{c}\text { GDM } \\
(\mathbf{n}=\mathbf{1 1 0})\end{array}$ & $\begin{array}{c}\text { Healthy } \\
(\mathbf{n}=\mathbf{1 1 0})\end{array}$ & P-value \\
\hline $\begin{array}{l}\text { WBC } \\
\left(\times 10^{3} / \mu m\right)\end{array}$ & $8.90 \pm 2.00$ & $9.44 \pm 2.00$ & $8.44 \pm 1.90$ & 0.00 \\
$\begin{array}{c}\text { Neutrophil } \\
(\%)\end{array}$ & $70.5 \pm 7.4$ & $69.8 \pm 7.8$ & $71.1 \pm 7.0$ & 0.20 \\
$\begin{array}{l}\text { Lymphocyte } \\
\quad \%)\end{array}$ & $24.9 \pm 6.8$ & $24.8 \pm 7.1$ & $24.9 \pm 7.0$ & 0.90 \\
$\begin{array}{l}\text { Platelet } \\
\left(\times 10^{3} / \mu m\right)\end{array}$ & $213.0 \pm 59.8$ & $233.0 \pm 62.6$ & $193.3 \pm 49.5$ & 0.00 \\
MPV (fL) & $9.80 \pm 1.50$ & $10.22 \pm 1.50$ & $9.45 \pm 1.58$ & 0.00 \\
PCT (\%) & $0.20 \pm 0.06$ & $0.23 \pm 0.06$ & $0.17 \pm 0.05$ & 0.00 \\
MPV.PLT ratio & $4.97 \pm 1.60$ & $4.73 \pm 1.66$ & $5.20 \pm 1.61$ & 0.03 \\
NLR & $3.10 \pm 1.50$ & $3.25 \pm 1.96$ & $3.06 \pm 1.04$ & 0.86 \\
PLR & $9.20 \pm 4.80$ & $10.39 \pm 6.00$ & $8.14 \pm 2.90$ & 0.00 \\
Blood group & - & - & - & 0.38 \\
Rh & - & - & - & 0.03
\end{tabular}

Values are presented as mean \pm standard deviation.

GDM, gestational diabetes mellitus; WBC, white blood cell; MPV, mean platelet volume; PCT, plateletcrit; PLT, platelet; NLR, neutrophil to lymphocyte ratio; PLR, platelet to lymphocyte ratio. nal health. This can remind healthcare providers of neonatal and maternal health and prevent inappropriate outcomes.

Platelet indicators, which are platelet activation biomarkers, allow the performance of a wide range of clinical studies with various diagnostic values and prognoses without additional cost. Among the PCT, MPV, and PDW platelet indices, a group of platelet parameters are reported in the CBC assay [15]. Besides the known platelet functions of homeostasis and thrombosis, a large number of studies have shown that platelets play an important role in intercellular communication, inflammatory activity, and immunization [23]. The results of studies by Gorar et al. [21], Sahbaz et al. [24],and Çeltik et al. [25] showed that women with GDM had significantly higher values of platelet and MPV than healthy pregnant women in the second trimester of pregnancy,

Table 3. Association between platelet and inflammatory indices and gestational diabetes mellitus using logistic regression analysis

\begin{tabular}{lccc}
\hline Variables & OR & \multicolumn{1}{c}{$\mathbf{9 5 \%} \mathbf{C l}$} & $\boldsymbol{P}$-value \\
\hline PCT & 2.48 & $4.052-15.202$ & 0.00 \\
PLT & 1.01 & $1.009-1.022$ & 0.00 \\
MPV & 1.56 & $1.267-1.930$ & 0.00 \\
WBC & 1.13 & $0.998-1.366$ & 0.00 \\
\hline
\end{tabular}

$\mathrm{OR}$, odds ratio; $\mathrm{Cl}$, confidence interval; $\mathrm{PCT}$, plateletcrit; $\mathrm{PLT}$, platelet; MPV, mean platelet volume; WBC, white blood cell.

Table 4. Detection rate of minimum and maximum plateletcrit (PCT) percentages

\begin{tabular}{lcc}
\hline PCT & Sensitivity & Specificity \\
\hline 0.14 & 96.36 & 30.00 \\
0.15 & 93.64 & 38.18 \\
0.16 & 90.00 & 48.18 \\
0.17 & 80.91 & 56.36 \\
0.18 & 74.55 & 64.55 \\
0.19 & 67.27 & 70.00 \\
0.20 & 62.73 & 78.18 \\
0.21 & 50.91 & 80.00 \\
0.22 & 45.45 & 83.64 \\
0.23 & 41.82 & 86.36 \\
0.24 & 36.36 & 89.09 \\
0.25 & 36.36 & 93.64 \\
0.26 & 28.18 & 94.55
\end{tabular}

The point of 0.20 for the PCT variable had the highest sensitivity and specificity. 


\section{Obstetrics \& Gynecology Science}

Mahta Abbasi Fashami, et al. Platelets and gestational diabetes mellitus

which was similar to the results of the present study. However, Erdoğan et al. [26] found no association between MPV and GDM. The reason for this result was the low number of samples compared to the other 3 studies.

PCT, as the product of platelet and MPV, provides complete
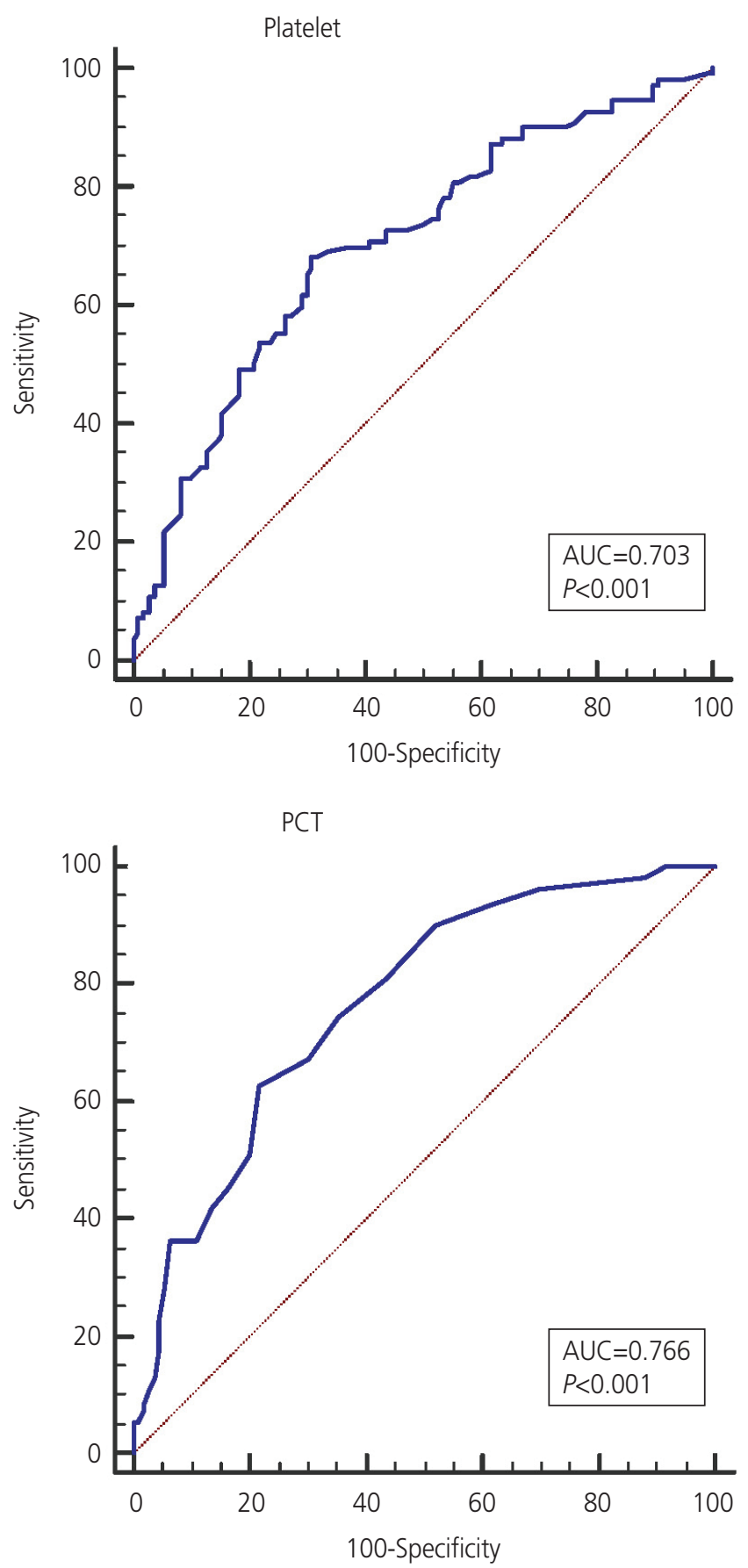

information about the total platelet mass and is clinically more valuable than either platelet or MPV [24,27]. The findings of studies by Sahbaz et al. [24] and Erdoğan et al. [26] showed that pregnant women with GDM had significantly higher PCT levels than healthy pregnant women, which was
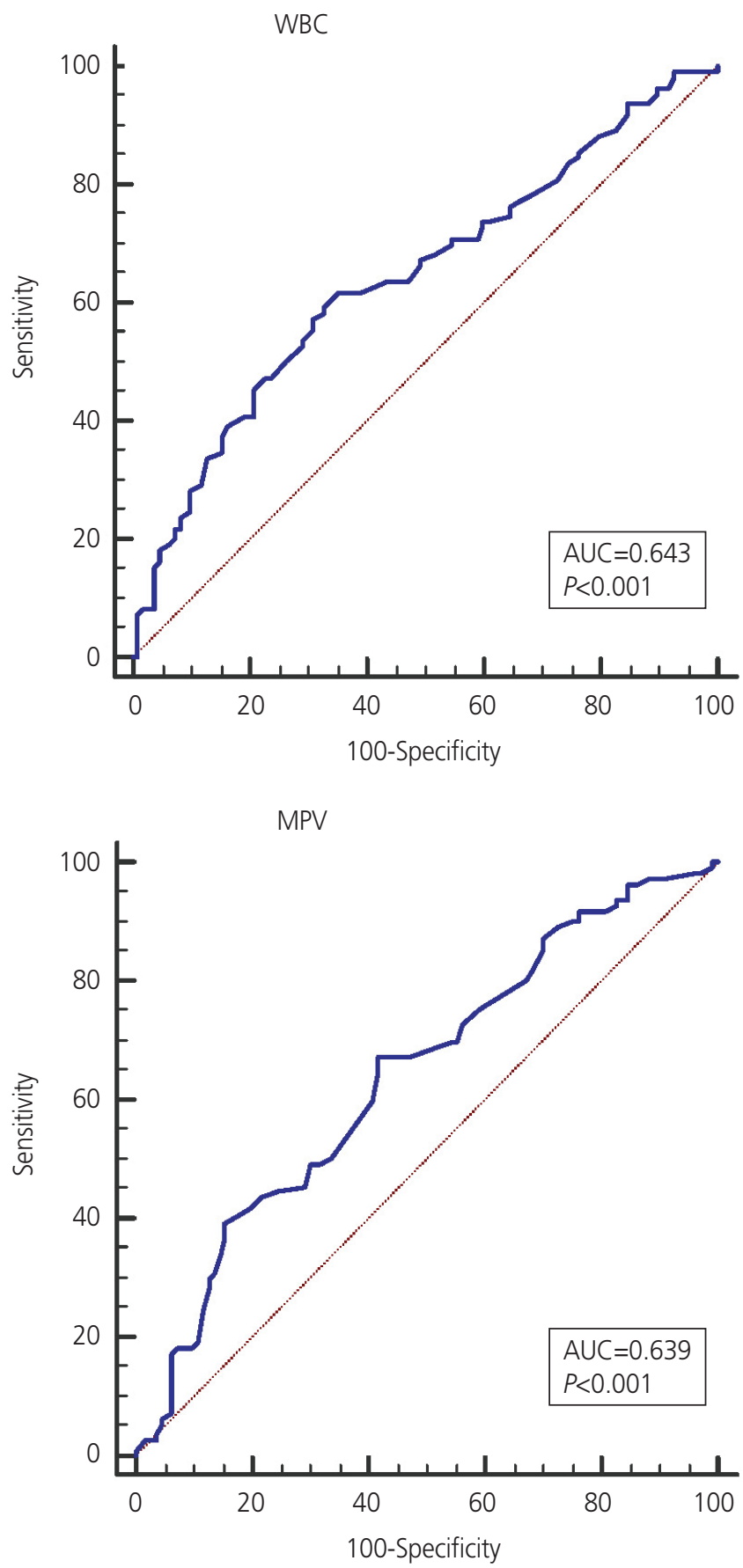

Fig. 1. Receiver operating characteristic curve of white blood cell (WBC) count, platelet count, mean platelet volume (MPV), and plateletcrit (PCT). AUC, area under the curve. 


\section{Obstetrics \& Gynecology Science}

Vol. 63, No. 2, 2020

consistent with the results of this study. Moreover, in the Sahbaz et al.'s study [24], PCT was the most powerful predictor of GDM in the second semester.

$M P R$, a new indicator for predicting inflammation, is a sign of a bad outcome $[28,29]$. The results of the study conducted by Duman et al. [28] showed that MPR levels were significantly higher in people with type 2 diabetes than in healthy individuals. This finding was consistent with the results of our study.

Pattanathaiyanon et al. [30] showed that higher numbers of leukocytes at the beginning of pregnancy were associated with a greater risk of developing GDM. The result of the study by Sargın et al. [14] suggested that WBC, neutrophil, and lymphocyte parameters in pregnant women with GDM were higher than those in healthy pregnant women. In the present study, only WBC was significantly correlated with GDM, and the findings regarding lymphocytes and neutrophils were in agreement with those of the Sargin et al.'s study [14]. Gorar et al. [21] reported that none of the 3 variables were significantly correlated with GDM.

On the other hand, inflammation has been reported in the pathogenesis of GDM. For example, Gomes et al. [31] and Catalano [32] showed that 2 inflammatory cytokines in GDM, specifically interleukin- 6 and tumor necrosis factor-a, were increased, while that of interleukin-10 was decreased. NLR and PLR have been introduced as inflammatory factors, and their associations with cardiovascular, pulmonary and other malignancies have been reported [33-36]. The findings of the Sahbaz et al. [24] study suggested a significant correlation between increased levels in women with GDM compared with healthy pregnant women. In a study, only PLR had a significant correlation with GDM. In the Sargın et al. [14] study, no NLR or PLR variables were associated with the incidence of GDM.

Saadati et al. [37] reported that the blood types did not differ significantly between groups, consistent with the results of our research. Most women with GDM have blood type A, but in this study, women with blood type $\mathrm{O}$ were more commonly affected. Shimodaira et al. [38] reported a correlation between blood type and GDM. In women with blood type $A B$, the risk of developing GDM was reported to be higher, which contradicted with the results of the $p$ resent study. The findings of the study by Huidobro et al. [39] showed no correlation between maternal blood sugar and GDM, which was in contrast to the results of this study. Such a difference in results seems due to differences in the research environment such as Iran, Japan, and Chile, as well as sex differences. In the present study, according to the distribution of $\mathrm{Rh}$ in the Iranian population, a positive Rh status was much more abundant than a negative Rh status. In addition, the difference between the positive and negative groups was negligible. As a result, this index has no significant relationship with the incidence of GDM.

One of the limitations of this study was its cross-sectional design, although the case-control design and group matching aids the analysis and confirmation of the correlations between the study variables. Other medical and obstetric variables were reported based on their midwifery files and through interviews. Future studies using the cohort design (a futuristic cohort) of changes in inflammatory and platelet factors in the first trimester and follow-up to the end of pregnancy are suggested.

In conclusion, the findings of this study confirmed the presence of a direct and significant correlation between platelet and inflammatory indices in the $\mathrm{CBC}$ test in the second trimester of pregnancy and GDM. WBC, platelet, MPV, PCT, $M P R$, and PLR values were higher in women with GDM than in healthy pregnant women. PCT had the strongest association with the occurrence of GDM in the second semester, which had special clinical significance. Given the importance of an early diagnosis of GDM, the need for similar studies in the first trimester of pregnancy can improve pregnancy outcomes using early intervention.

\section{Acknowledgements}

The author appreciates the collaboration of the research deputy of Shahid Beheshti University of Medical Sciences, Shohda-e-Tajrish Hospital staff, and all the pregnant women who participated in this study.

\section{Conflict of interest}

No potential conflict of interest relevant to this article was reported. 


\section{Obstetrics \& Gynecology Science}

Mahta Abbasi Fashami, et al. Platelets and gestational diabetes mellitus

\section{Ethical approval}

This article was based on a master's degree thesis under the ethics code of IR.SBMU.PHNM.1396.755. The study was approved by the Institutional Review Board of School of Pharmacy and Nursing and Midwifery-Shahid Beheshti University of Medical Sciences (IRB No. IR.SBMU.PHNM.1396.755) and performed in accordance with the principles of the Declaration of Helsinki.

\section{Patient consent}

The patients provided written informed consent for the publication and the use of their images.

\section{References}

1. Cunningham FG. Williams obstetrics. New York (NY): McGraw-Hill Education; 2018.

2. Durnwald C. Diabetes mellitus in pregnancy: screening and diagnosis [Internet]. Waltham (MA): UpToDate; 2018 [Accessed 2018 Aug 4]. Available from: https:// www.uptodate.com/contents/diabetes-mellitus-in-pregnancy-screening-and-diagnosis.

3. Melchior H, Kurch-Bek D, Mund M. The prevalence of gestational diabetes: a population-based analysis of a nationwide screening program. Dtsch Arztebl Int 2017;114:412-8.

4. Rahimi M, Karami Moghadam F. The prevalence of gestational diabetes mellitus and its related risk factors using one-step method in Kermanshah, 2016. Iran J Obstet Gynecol Infertil 2017;20:1-4.

5. Ramezani S, Ahmadi M, Saqhafi H, Alipoor M. Association of pregnancy-associated plasma protein a (PAPP-A) and gestational diabetes. Iran J Obstet Gynecol Infertil 2017;20:61-9.

6. Committee on Practice Bulletins-Obstetrics. ACOG Practice Bulletin No. 190: gestational diabetes mellitus. Obstet Gynecol 2018;131:e49-64.

7. Kebapcilar L, Kebapcilar AG, Ihan TT, Ipekci SH, Baldane $\mathrm{S}$, Pekin $\mathrm{A}$, et al. Is the mean platelet volume a predictive marker of a low apgar score and insulin resistance in gestational diabetes mellitus? A retrospective case- control study. J Clin Diagn Res 2016;10:OC06-10.

8. Gorgal R, Gonçalves E, Barros M, Namora G, Magalhães $A$, Rodrigues $T$, et al. Gestational diabetes mellitus: a risk factor for non-elective cesarean section. J Obstet Gynaecol Res 2012;38:154-9.

9. International Diabetes Federation; Madras Diabetes Research Foundation. Management of gestational diabetes in the community. Training manual for community health workers [Internet]. Brussels: International Diabetes Federation; [Accessed 2018 Aug 4]. Available from: https://www.idf.org/e-library/guidelines.html.

10. Beneventi F, Simonetta $M$, Lovati E, Albonico G, Tinelli $C$, Locatelli $E$, et al. First trimester pregnancy-associated plasma protein-A in pregnancies complicated by subsequent gestational diabetes. Prenat Diagn 2011;31:523-8.

11. Mertoglu C, Gunay M. Neutrophil-Lymphocyte ratio and Platelet-Lymphocyte ratio as useful predictive markers of prediabetes and diabetes mellitus. Diabetes Metab Syndr 2017;11 Suppl 1:S127-31.

12. Coates TD. Approach to the patient with neutrophilia [Internet]. Waltham (MA): UpToDate; [Accessed 2019 Feb 7]. Available from: https://www.uptodate.com/contents/approach-to-the-patient-with-neutrophilia.

13. Choi JL, Li S, Han JY. Platelet function tests: a review of progresses in clinical application. Biomed Res Int 2014;2014:456569.

14. Sargın MA, Yassa M, Taymur BD, Celik A, Ergun E, Tug N. Neutrophil-to-lymphocyte and platelet-to-lymphocyte ratios: are they useful for predicting gestational diabetes mellitus during pregnancy? Ther Clin Risk Manag 2016;12:657-65.

15. Budak YU, Polat M, Huysal K. The use of platelet indices, plateletcrit, mean platelet volume and platelet distribution width in emergency non-traumatic abdominal surgery: a systematic review. Biochem Med (Zagreb) 2016;26:178-93.

16. McPherson RA, Pincus MR. Henry's clinical diagnosis and management by laboratory methods. St. Louis (MO): Elsevier; 2017.

17. Zhou Z, Chen H, Sun M, Ju H. Mean platelet volume and gestational diabetes mellitus: a systematic review and meta-analysis. J Diabetes Res 2018;2018:1985026.

18. Yang $H$, Zhu C, Ma Q, Long Y, Cheng Z. Variations of blood cells in prediction of gestational diabetes mellitus. J Perinat Med 2015;43:89-93. 


\section{Obstetrics \& Gynecology Science}

Vol. 63, No. 2, 2020

19. Chen $X$, Fang $L$, Lin $H$, Shen $P$, Zhang $T$, Li $H$, et al. The relationship between type 2 diabetes and platelet indicators. Iran J Public Health 2017;46:1211-6.

20. Jiang $H$, Yan WH, Li CJ, Wang AP, Dou JT, Mu YM. Elevated white blood cell count is associated with higher risk of glucose metabolism disorders in middle-aged and elderly Chinese people. Int J Environ Res Public Health 2014;11:5497-509.

21. Gorar S, Abanonu GB, Uysal A, Erol O, Unal A, Uyar $S$, et al. Comparison of thyroid function tests and blood count in pregnant women with versus without gestational diabetes mellitus. J Obstet Gynaecol Res 2017:43:848-54.

22. Akobeng AK. Understanding diagnostic tests 3: receiver operating characteristic curves. Acta Paediatr 2007;96:644-7.

23. Yun SH, Sim EH, Goh RY, Park JI, Han JY. Platelet activation: the mechanisms and potential biomarkers. BioMed Res Int 2016;2016:9060143.

24. Sahbaz A, Cicekler H, Aynioglu O, Isik H, Ozmen U. Comparison of the predictive value of plateletcrit with various other blood parameters in gestational diabetes development. J Obstet Gynaecol 2016;36:589-93.

25. Çeltik A, Akıncı B, Demir T. Mean platelet volume in women with gestational diabetes. Turk J Endocrinol Metab 2016;20:48-53.

26. Erdoğan S, Ozdemir O, Doğan HO, Sezer $S$, Atalay CR, Meriç F, et al. Liver enzymes, mean platelet volume, and red cell distribution width in gestational diabetes. Turk J Med Sci 2014;44:121-5.

27. Chandrashekar V. Plateletcrit as a screening tool for detection of platelet quantitative disorders. J Hematol 2013;2:22-6.

28. Duman TT, Aktas G, Atak B, Kocak MZ. Is mean platelet volume to platelet ratio a promising indicator of diabetic regulation in type 2 diabetes mellitus? J Med Res 2018;4:137-9.

29. Shin DH, Rhee SY, Jeon HJ, Park JY, Kang SW, Oh J. An increase in mean platelet svolume/platelet count ratio is associated with vascular access failure in hemodialysis patients. PLoS One 2017;12:e0170357.

30. Pattanathaiyanon P, Phaloprakarn C, Tangjitgamol S. Comparison of gestational diabetes mellitus rates in women with increased and normal white blood cell counts in early pregnancy. J Obstet Gynaecol Res 2014;40:976-82.

31. Gomes CP, Torloni MR, Gueuvoghlanian-Silva BY, Alexandre SM, Mattar R, Daher S. Cytokine levels in gestational diabetes mellitus: a systematic review of the literature. Am J Reprod Immunol 2013;69:545-57.

32. Catalano PM. Trying to understand gestational diabetes. Diabet Med 2014;31:273-81.

33. Demir M, Duyuler PT, Guray U, Celik MC. Platelet to lymphocyte ratio on admission and prognosis in patients with acute cardiogenic pulmonary edema. J Emerg Med 2018;55:465-71.

34. Agameya AM, Labib K, Moiety F. Using platelet-tolymphocyte ratio as a diagnostic marker in malignant ovarian tumors. Int J Reprod Contracept Obstet Gynecol 2018;7:2089-92.

35. Durmus E, Kivrak T, Gerin F, Sunbul M, Sari I, Erdogan O. Neutrophil-to-lymphocyte ratio and platelet-to-lymphocyte ratio are predictors of heart failure. Arq Bras Cardiol 2015;105:606-13.

36. Forget $P$, Khalifa C, Defour JP, Latinne D, Van Pel MC, De Kock M. What is the normal value of the neutrophil-tolymphocyte ratio? BMC Res Notes 2017;10:12.

37. Saadati N, Anafcheh M, Ahmadzadeh B, Albookordi M, Najafian M. Effect of blood group, height, and weight gain during pregnancy on gestational diabetes mellitus. Iran J Obstet Gynecol Infertil 2018;21:34-42.

38. Shimodaira M, Yamasaki T, Nakayama T. The association of maternal $A B O$ blood group with gestational diabetes mellitus in Japanese pregnant women. Diabetes Metab Syndr 2016;10:S102-5.

39. Huidobro M A, Torres C D, Paredes F. Association of abo blood groups with gestational diabetes mellitus. Rev Med Chil 2017;145:431-5. 